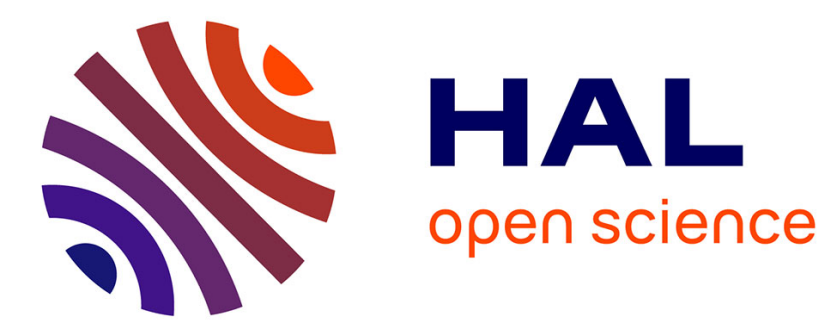

\title{
Numerical study of the influence of the convective heat transfer on the dynamical behaviour of a phase change material wall
}

Damien David, F. Kuznik, J.-J. Roux

\section{- To cite this version:}

Damien David, F. Kuznik, J.-J. Roux. Numerical study of the influence of the convective heat transfer on the dynamical behaviour of a phase change material wall. Applied Thermal Engineering, 2011, 31, pp.3117-3124. 10.1016/j.applthermaleng.2011.04.001 . hal-00683866

\section{HAL Id: hal-00683866 https://hal.science/hal-00683866}

Submitted on 9 Jun 2014

HAL is a multi-disciplinary open access archive for the deposit and dissemination of scientific research documents, whether they are published or not. The documents may come from teaching and research institutions in France or abroad, or from public or private research centers.
L'archive ouverte pluridisciplinaire HAL, est destinée au dépôt et à la diffusion de documents scientifiques de niveau recherche, publiés ou non, émanant des établissements d'enseignement et de recherche français ou étrangers, des laboratoires publics ou privés. 


\title{
Numerical Study of the Influence of the Convective Heat Transfer on the Dynamical Behaviour of a Phase Change Material Wall
}

\author{
Damien David ${ }^{\mathrm{a}, \mathrm{b}, \mathrm{c}, *}$, Frédéric Kuznik ${ }^{\mathrm{a}, \mathrm{b}, \mathrm{c}}$, Jean-Jacques Roux ${ }^{\mathrm{a}, \mathrm{b}, \mathrm{c}}$ \\ ${ }^{a}$ CETHIL, UMR5008, F-69621, Villeurbanne, France \\ ${ }^{b}$ Université de Lyon \\ ${ }^{c}$ INSA-Lyon
}

\begin{abstract}
In construction, the use of Phase Change Materials (PCM) allows the storage/release of energy from solar radiation and internal loads. The application of such materials for lightweight construction (e.g., a wood house) makes it possible to improve thermal comfort and reduce energy consumption. The heat transfer process between the wall and the indoor air is convection. In this paper, we have developed a numerical model to evaluate several convective heat transfer correlations from the literature for natural, mixed and forced convection flows. The results show that the convective heat transfer highly influences the storage/release process in case of PCM walls. For the natural convection, the numerical results are highly dependent on the correlation used and the results may vary up to $200 \%$. In the case of mixed and forced convection flows, the higher is the velocity, the more important is the storage capacity.
\end{abstract}

Keywords: Thermal Energy Storage, Phase Change Material, Convective Heat Transfer Coefficient.

\section{Introduction}

Nowadays, thermal energy storage systems are essential for reducing dependency on fossil fuels and then contributing to a more efficient environmentally benign energy use [1]. As demand in thermal comfort of buildings grows increasingly, the energy consumption is correspondingly increasing. For example, in France, the energy consumption of buildings has increased by $30 \%$ the last 30 years. Housing and tertiary buildings are responsible for the consumption of approximatively $46 \%$ of all energies and approximatively $19 \%$ of the total $\mathrm{CO}_{2}$ emissions [2].

Thermal energy storage can be accomplished either by using sensible heat storage or latent heat storage. Sensible heat storage has been used for centuries by builders to store/release passively thermal energy, but a much larger volume of material is required to store the same

*Corresponding author. Tel.: +33-472-438-461; Fax: +33-472-438-522

Email address: damien.david@insa-lyon.fr (Damien David) 
amount of energy in comparison to latent heat storage. The principle of the phase change material (PCM) use is simple. As the temperature increases, the material changes phase from solid to liquid. The reaction being endothermic, the PCM absorbs heat. Similarly, when the temperature decreases, the material changes phase from liquid to solid. The reaction being exothermic, the PCM desorbs heat.

The main disadvantage of light weight buildings is their low thermal mass. Obviously, they tend to large temperature fluctuations due to external cooling, solar heat or internal loads. Using PCM material in such building walls can decrease the temperature fluctuations, particularly in case of solar radiations loads. It is then a potential method for reducing energy consumption in passively designed buildings. This tendency is confirmed by numerous papers available in the literature during the last 20 years. For a review, see in [3], [4], [5] and more recently [6].

Nowadays, numerical modeling is mandatory to assess new buildings at the design stage. The building is a quite complex object going trough to internal and external thermal influences. External influences are due to the local external weather. Internal influences come from solar radiative flux entering the building and internal loads. The heat transfer between the PCM wall and the air is due to convection. For external walls surface, the convective heat transfer is driven by forced convection, but as the walls are insulated, this transfer process is not prevalent. The convective heat transfer between the internal face of the wall and the indoor air is important to evaluate the storage/release process in PCM. The objective of this paper is to evaluate the sensitivity of the storage/release process depending on the convective heat transfer coefficient.

\section{Description of the wall tested}

\subsection{Composite PCM wallboard tested}

The product tested, ENERGAIN ${ }^{\circledR}$, has been developed by the Dupont de Nemours Society . It is obtained from a mixture of $60 \%$ paraffin and $40 \%$ copolymer. This mixture is heated until both materials melt and blend in each other. Then it is cooled at the ambient temperature, resulting in a homogeneous solid material. The final form of the composite PCM (see figure 1) is a flexible sheet of $5 \mathrm{~mm}$ thickness which density is about $900 \mathrm{~kg} \cdot \mathrm{m}^{-3}$. The thickness of the PCM is the result of a commercial compromise and allows $77 \%$ of optimal efficiency obtained with $5 \mathrm{~mm}$ thickness [7].

The thermal conductivity has been measured using guarded hot-plate apparatus [8]. The thermal conductivity is $0.22 W \cdot m^{-1} \cdot K^{-1}$ in liquid phase and decreases to about $0.18 W \cdot m^{-1} \cdot K^{-1}$ in solid phase.

The composite PCM enthalpy has been measured using a differential scanning calorimeter (DSC) as illustrated in figure 2; the heating and cooling rate being $0.05 \mathrm{Kmn}^{-1}$. The thermal analysis is presented for the range $\left[-20^{\circ} \mathrm{C} ; 35^{\circ} \mathrm{C}\right]$. Two curves are presented: the freezing curve (cooling from $35^{\circ} \mathrm{C}$ to $-20^{\circ} \mathrm{C}$ ) and the melting curve (heating from $-20^{\circ} \mathrm{C}$ to $35^{\circ} \mathrm{C}$ ).

From the DSC curves, melting and freezing temperatures are $13.6^{\circ} \mathrm{C}$ and $23.5^{\circ} \mathrm{C}$ respectively. The measured latent heats of melting and freezing are respectively $107.5 \mathrm{~kJ} / \mathrm{kg}$ and $104.5 \mathrm{~kJ} / \mathrm{kg}$; and $72.4 \mathrm{~kJ} / \mathrm{kg}$ and $71 \mathrm{~kJ} / \mathrm{kg}$ for the range $\left[5^{\circ} \mathrm{C} ; 30^{\circ} \mathrm{C}\right]$. The composite PCM 


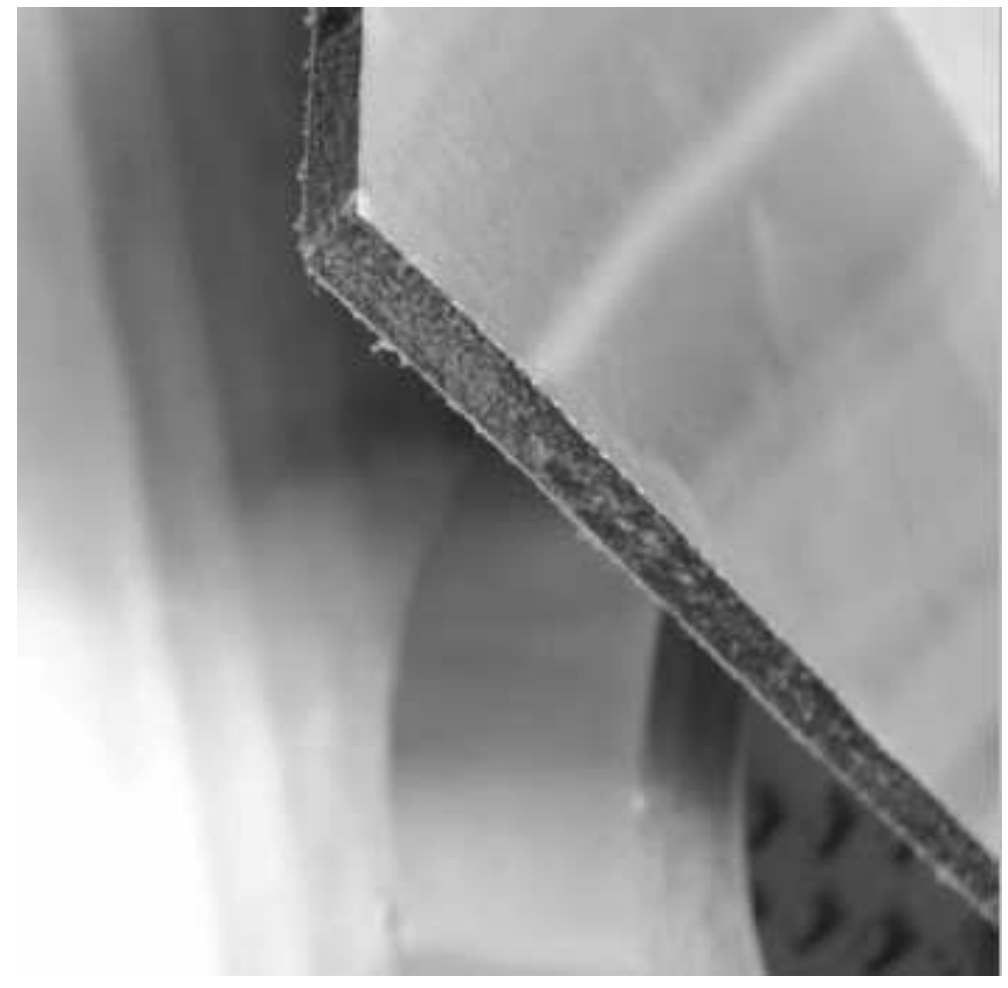

Figure 1: Dupont de Nemours PCM composite wallboard. 


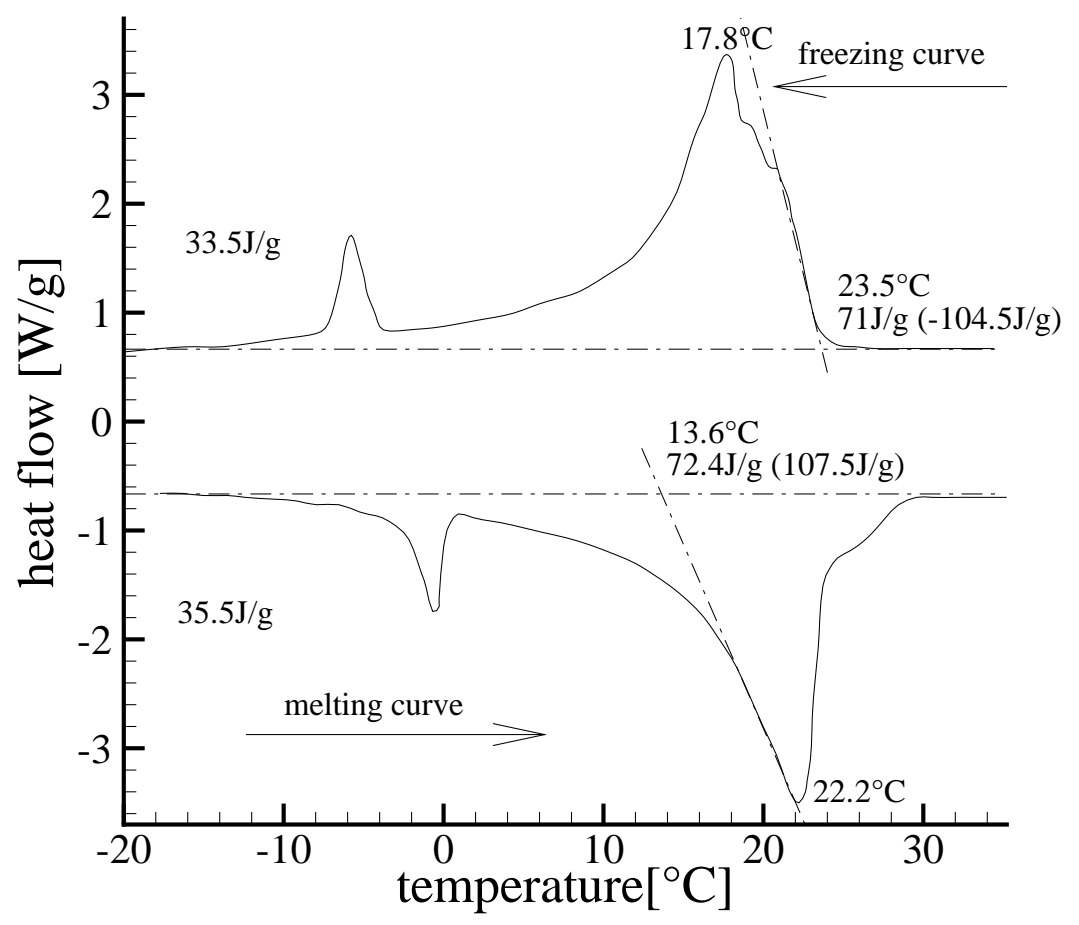

Figure 2: Differential scanning calorimeter melting and freezing curves for the composite PCM. 


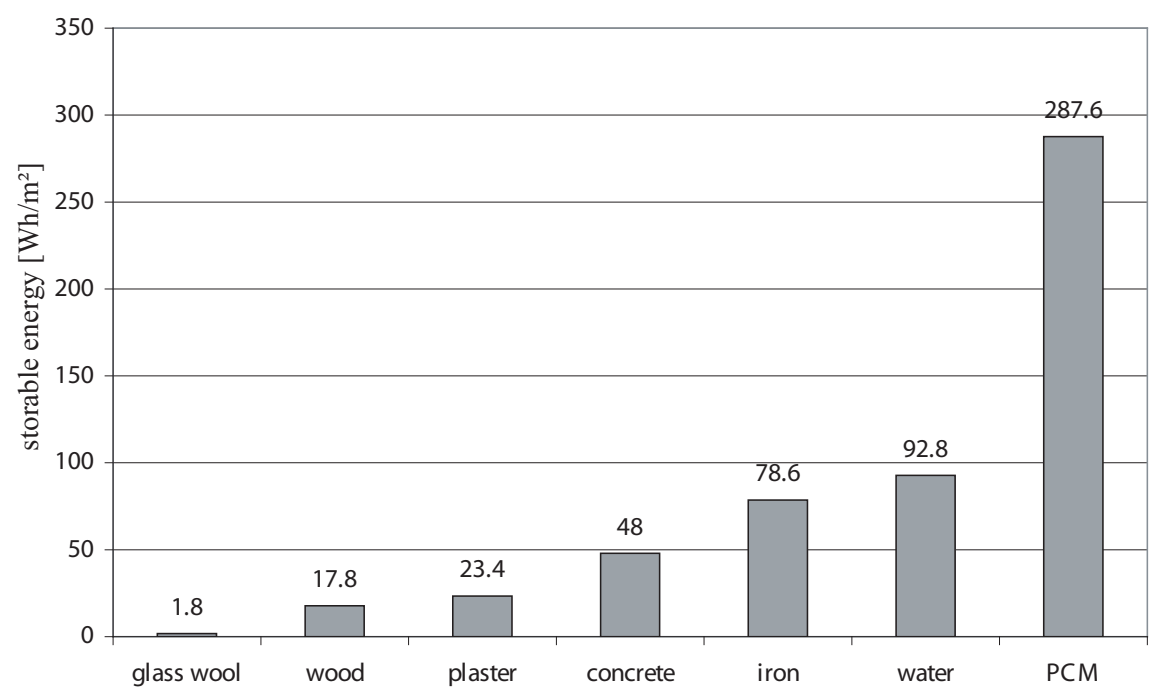

Figure 3: Comparative values storage capacity of building materials in the same conditions of temperature variation and of thickness.

described in this article has an important potential of thermal energy storage in building walls. This particularity is due to the possibility to incorporate much more PCM in the polymeric material than in a traditional construction material, for example:

* $26 w t \%$ of fatty acids PCM in gypsum - see [9],

$\star 35 w t \%$ of paraffin in gypsum - see [10],

$\star 5.6 w t \%$ of butyl sterate PCM in concrete block; $8.6 w t \%$ of paraffine in concrete block - see [11].

Considering a temperature variation between $18^{\circ} \mathrm{C}$ and $26^{\circ} \mathrm{C}$, variation that is very common in low inertia building, the PCM stores about 3 times more energy than water and 6 times more energy than concrete (figure 3 ) for the same wall thickness.

\subsection{Studied configuration}

\subsubsection{General assumptions}

One important hypothesis used during the implementation is that heat transfer is unidirectional in building walls. This assumption is widely used for the thermal simulations of buildings.

The PCM wallboard is used in lightweight buildings (or caravans) to reduce room air temperature fluctuations, in particular when overheating occurs [12]. Then, the wall tested is composed, from the outside, of $2 \mathrm{~cm}$ of wood, an insulating material with a thickness $e_{i n s}=10 \mathrm{~cm}$, the PCM wallboard described previously with a thickness of $e_{P C M}=5 \mathrm{~mm}$ and $1 \mathrm{~cm}$ of plaster. A complete description of this test wall is shown in figure 4 , and the 


\begin{tabular}{lccc}
\cline { 2 - 4 } & $\begin{array}{c}\text { density } \\
{\left[\mathrm{kg} / \mathrm{m}^{3}\right]}\end{array}$ & $\begin{array}{c}\text { specific heat } \\
{[\mathrm{J} / \mathrm{kgK}]}\end{array}$ & $\begin{array}{c}\text { thermal conductivity } \\
{[\mathrm{W} / \mathrm{mK}]}\end{array}$ \\
\hline plaster & 825 & 1000 & 0.25 \\
wood plate & 500 & 1600 & 0.15 \\
insulating material & 15 & 1030 & 0.041 \\
\hline
\end{tabular}

Table 1: Thermophysical properties of the materials.

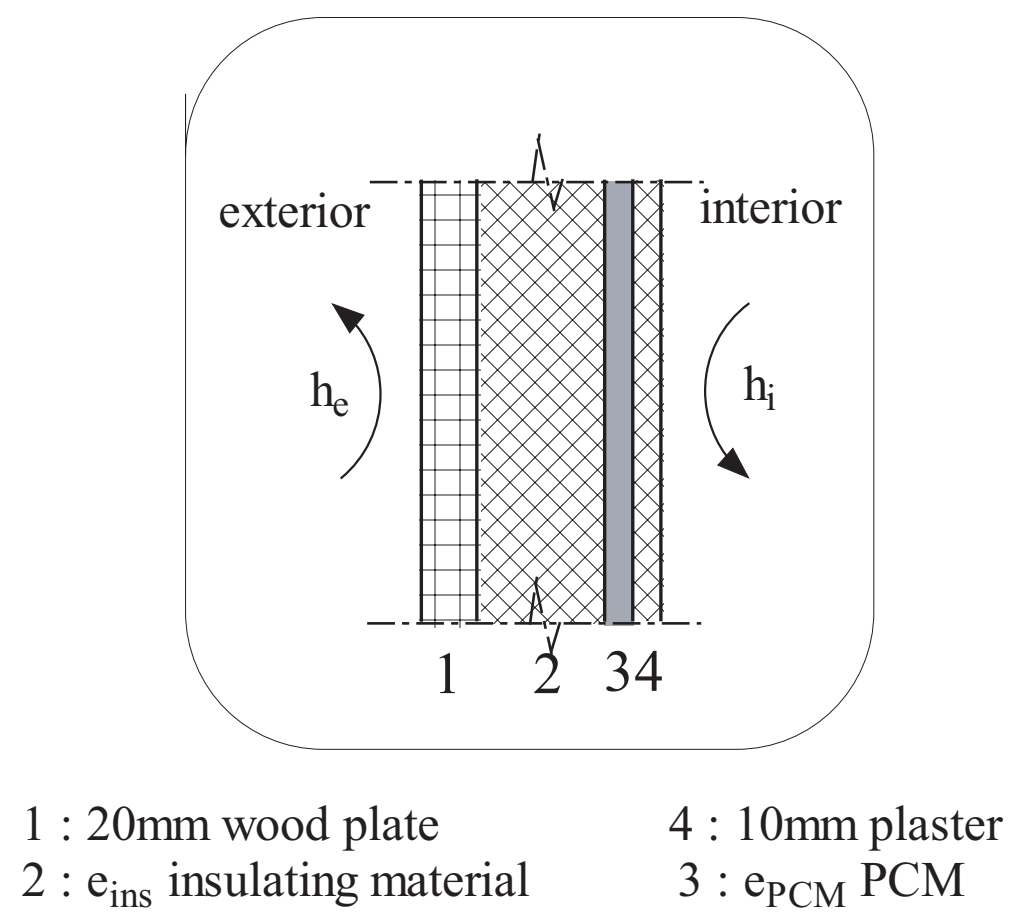

Figure 4: Test wall composition

thermophysical properties of the materials are given in table 1 . The exterior heat transfer coefficients $h_{e}$ is given by the French thermal rules [13]: $h_{e}=25 \mathrm{~W} / \mathrm{m}^{2} \mathrm{~K}$. The correlations for the interior heat transfer coefficient $h_{i}$ are given in the section 3 .

The insulation thickness $e_{i n s}=10 \mathrm{~cm}$ is chosen so that this thickness allows to fulfil the requirement of the French thermal rules [13] given by the U-value of the wall, $U<$ $0.47 \mathrm{~W} / \mathrm{m}^{2} \mathrm{~K}$. The $\mathrm{U}$-value is calculated via:

$$
\frac{1}{U}=\frac{1}{h_{e}}+\frac{e_{w p}}{\lambda_{w p}}+\frac{e_{i n s}}{\lambda_{i n s}}+\frac{e_{p}}{\lambda_{p}}+\frac{1}{h_{i}}
$$

\subsubsection{External conditions}

For the building configuration, outdoor boundary conditions and indoor thermal loads are specified while indoor air temperatures may change in time. The main outdoor conditions 


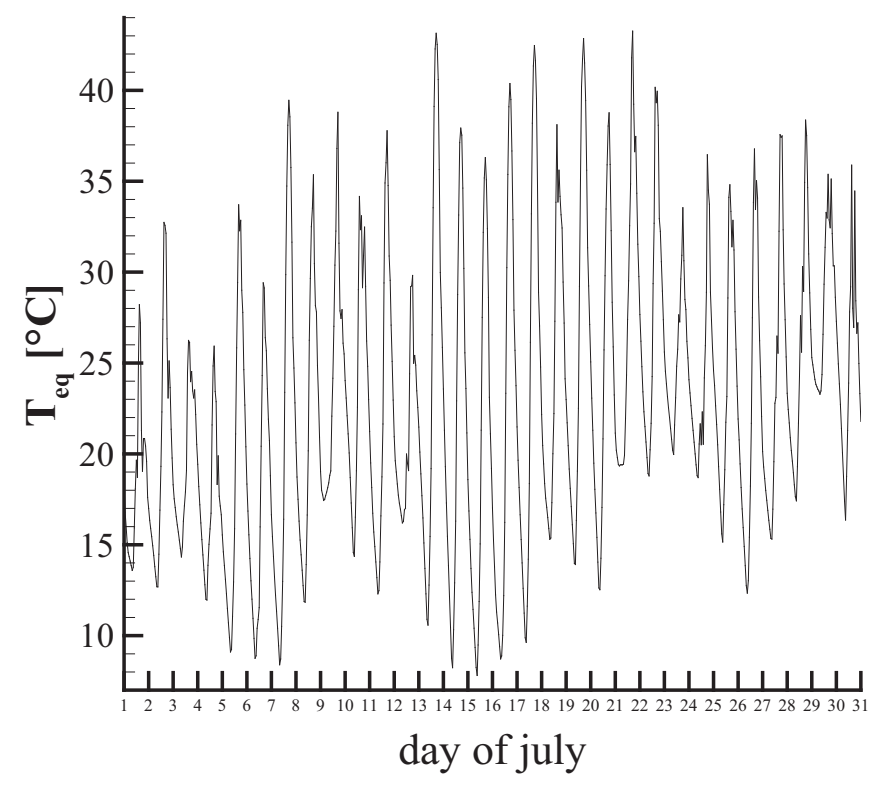

Figure 5: Equivalent temperature: vertical wall in Paris - July

are external air temperature and solar radiation. These conditions are taken into account using the equivalent temperature $T_{e q}$ calculated using:

$$
T_{e q}=T_{e}+\frac{\alpha S}{h_{e}}
$$

with $T_{e}$ the exterior air temperature, $S$ the total solar radiations, $\alpha$ the solar absorption coefficient of the surface and $h_{e}$ the exterior convective heat transfer.

Figure 5 shows the equivalent temperature calculated for a south vertical wall in Paris in July. From this figure, the assumption of a sinusoidal evolution for exterior equivalent air temperature can be used. Then the optimization process is held using a sinusoidal evolution of the exterior temperature between $15^{\circ} \mathrm{C}$ and $35^{\circ} \mathrm{C}$ and within a period of $24 \mathrm{~h}$.

\subsubsection{Internal conditions}

The interior air temperature is influenced by outdoor conditions, internal loads and, of course, the building composition. Similarly to the assumption used for exterior temperature, a sinusoidal evolution for the interior air temperature is used. For the interior temperature, the selected sinusoidal evolution is taken between $T_{i, \max }=24^{\circ} \mathrm{C}$ and $T_{i, \min }=20^{\circ} \mathrm{C}$, with a phase difference of $\tau=3 h$ with exterior air temperature. The boundary conditions are summarized in figure 6 . 


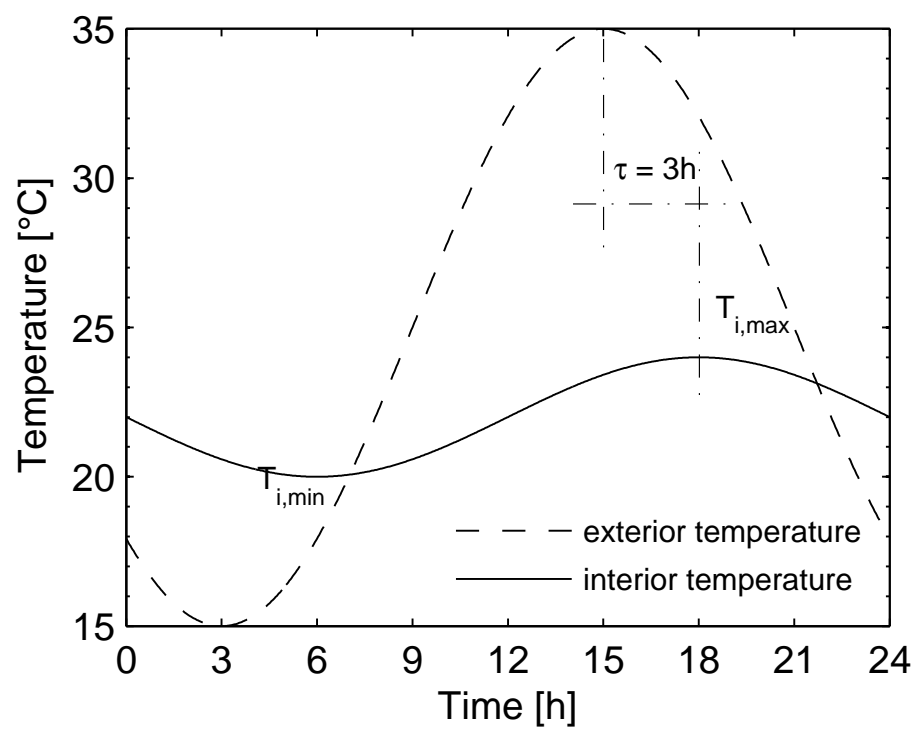

Figure 6: Air temperature boundary conditions

\section{The convection heat transfer coefficient in buildings}

The convection heat transfer along room surfaces is a very complex phenomenon. The first cause of this complexity is due to the flow regime in the boundary layer. Awbi [14] highlighted, with a smoke test, the presence of laminar and turbulent flows along building walls.

The convection at the surface of a building wall can not be considered locally as pure natural convection. The disposition of heat sources and ventilation systems in the room leads to a global air movement which influence locally the convective heat transfer.

\subsection{Studies from the literature}

The literature presents two methods to deal with the complexity of the heat transfer at the surface of building walls. The first method consists in measuring the temperatures and the heat flux in a real size test cell to obtain an expression of the mean heat transfer coefficient $h$. A large number of heating configurations and cell sizes has to be tested with this method in order to cover the wide range of configurations found in real buildings.

The second method is called the pseudo-theoretical method. It consists in a separate study of each phenomenon involved in the heat transfer at the surface of the wall. Each study leads to an expression of the convective heat transfer coefficient. Those expressions are then combined using a formula presented by Churchill and Usagi [15]. In order to combine two correlations $h_{1}$ and $h_{2}$, Churchill and Usagi propose the use of the equation 3 . The coefficient $n$ is determined from experimental data.

$$
h=\left[\left(h_{1}\right)^{n}+\left(h_{2}\right)^{n}\right]^{1 / n}
$$


Alamdari ans Hammond [16], combined two correlations for natural convection in laminar and turbulent regimes. They obtained the equation 4 . The term $\Delta T$ corresponds to the averaged value of the temperature difference between the surface of the wall and the air inside the room. $H$ is the height of the wall.

$$
h=\left[\left(1.51\left(\frac{|\Delta T|}{H}\right)^{1 / 4}\right)^{6}+\left(1.33|\Delta T|^{1 / 3}\right)^{6}\right]^{1 / 6}
$$

Awbi and Hatton [17] performed measurements in a $3 m \times 3 m \times 2.5 m$ test cell. The test cell shares a wall with a regulated room in which outdoor conditions are reproduced. Different heating configurations have been tested with a network of heating films, scattered on the surface of the different walls. The authors developed the correlation 5 from their measurement data. $D$ is the hydraulic diameter of the wall (surface divided by perimeter).

$$
h=1.823 \frac{|\Delta T|^{0.293}}{D^{0.121}}
$$

Liu and Awbi [18] performed measurements in the same test cell, including phase change materials in one of the walls. They observed a value of the convection coefficient along the PCM wall 2.3 times higher than the value predicted from the correlation 5:

$$
h=2.3 \times 1.823 \frac{|\Delta T|^{0.293}}{D^{0.121}}
$$

The French Thermal Regulation RT2005 [13] provides a value of the mean convective heat transfer coefficient equation equal to $7.7 \mathrm{~W} / \mathrm{m}^{2} \mathrm{~K}$. This value is compared, in the figure 7 , with the values provided by the correlations 4,5 , and 6 , for a $2.5 m$ wall, and for $\Delta T$ situated between $0^{\circ} \mathrm{C}$ and $5^{\circ} \mathrm{C}$.

Wallenten [19] noticed that the the expressions of the convection coefficient obtained so far with the pseudo theoretical method, give lower values than the heat coefficients measured in test cells. This observation is confirmed in the figure 7, the correlation from Alamdari and Hammond gives the lowest values for $h$. This is due to the fact that the authors don't take into consideration the global air movement in the room to build their correlation. The highest value of the convective heat transfer coefficient is the one provided by the French thermal regulation [13]. This value had been overestimated on purpose, because a high value of the convection coefficient is more restrictive for the design of highly insulated walls.

\subsection{Correlation for mixed convection in both laminar and turbulent regimes}

Two convection phenomena are overlapping each other along the surfaces of building rooms. The first one is the natural convection heat transfer, which is driven by the temperature difference $\Delta T$ between the surface of the wall and the air inside the room. The second one is the forced convection which is driven by the global air movement caused by heat and ventilation sources in the room. Thus, the convection at the surface of building walls can be considered locally as mixed convection, in the laminar and turbulent regimes. 


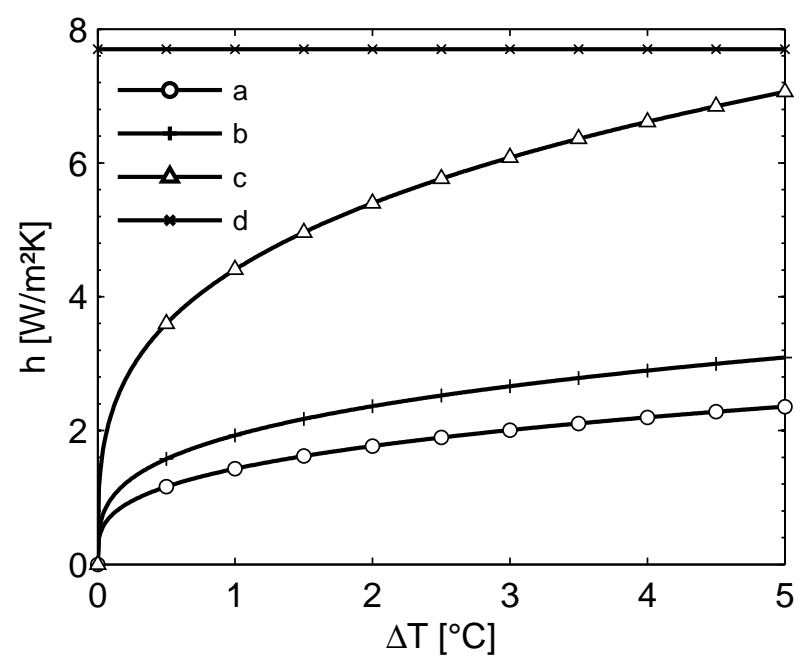

Figure 7: Comparison between the correlations of the literature for the convective heat transfer coefficient. a: Alamdari and Hammond [16], b: Awbi and Hatton [17], c: Liu and Awbi [18], d: RT2005 [13].

Chen et al. [20, 21] have built two correlations, one for mixed convection in the laminar regime, and one for mixed convection in the turbulent regime. The correlations from Chen et al. are combined in the equation 7, using Churchill and Usagi's formalism, in order to obtain a correlation valid for both laminar and turbulent regimes. The value of the coefficient $n$ is identical to the value $n=6$ used by Alamdari and Hammond [16] to combine the laminar and the turbulent flow regimes for natural convection. The parameter $V$ is the mean vertical velocity of the ambient medium in front of the wall.

$$
\begin{aligned}
& h=\left\{\left[\left(4.54\left(\frac{|V|}{H}\right)^{1 / 2}\right)^{3} \pm\left(1.335\left(\frac{|\Delta T|}{H}\right)^{1 / 4}\right)^{3}\right]^{2}+\right. \\
& {\left.\left[\left(5.41\left(\frac{|V|^{4}}{H}\right)^{1 / 5}\right)^{3} \pm\left(1.293(|\Delta T|)^{1 / 3}\right)^{3}\right]^{2}\right\}^{1 / 6} }
\end{aligned}
$$

If $V$ and $\Delta T$ have the same sign, the air velocity due to the global movement in the room has the same direction than the air velocity due to natural convection. Forced and natural convection are assisting each other, and the signs in the correlation 7 are + . Other wise, the air velocity due to the global movement is opposed to of the air velocity due to natural convection. Forced and natural convection are opposed to each other, and the signs in the correlation 7 are - .

The figure 8 shows values of the convection coefficient calculated with the correlation 7 , for a $2.5 \mathrm{~m}$ high wall, with $\Delta T$ situated between $0^{\circ} \mathrm{C}$ and $5^{\circ} \mathrm{C}$, and with $V$ situated between $-0.4 \mathrm{~m} / \mathrm{s}$ and $0.4 \mathrm{~m} / \mathrm{s}$. 


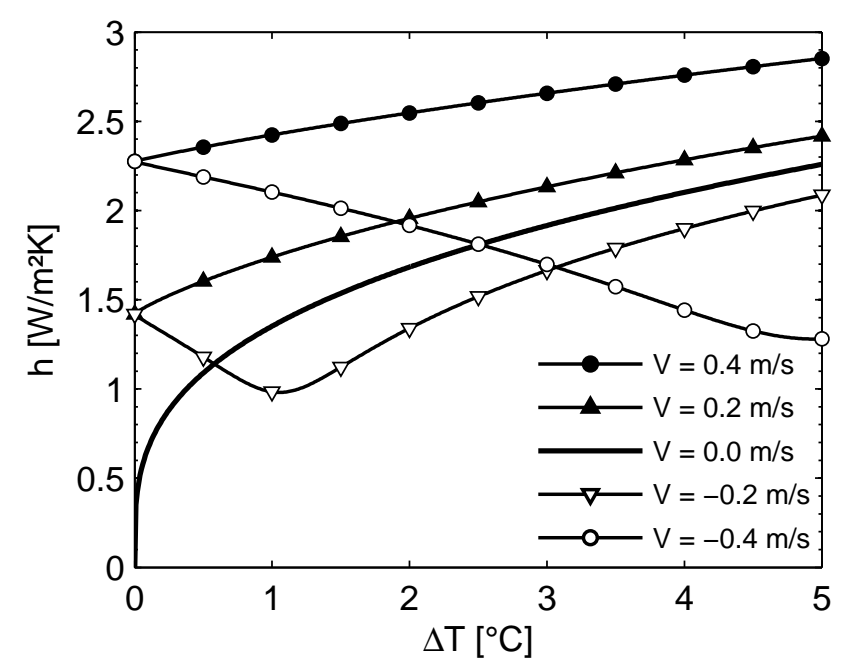

Figure 8: Values of convective heat transfer coefficient for mixed convection.

The curve $V=0$ corresponds to pure natural convection. When $V \neq 0$, the curves present two asymptotic behaviors. For small values of $\Delta T$, the forced convection terms are dominant in equation 7. The convection coefficient is higher for mixed convection than for natural convection. The limiting case $\Delta T=0$ corresponds to pure forced convection. For high values of $\Delta T$, the natural convection terms are dominant in equation 7 . The mixed convection curve gets closer to the natural convection curve when the temperature difference increases.

When $V>0$, natural and forced convection assist each other and the convection coefficient is always higher for mixed convection than for natural convection. When $V<0$, the behavior of the convection coefficient presents two phases. During the first phase, its value decreases from the pure forced convection value, at $\Delta T=0$, to a minimum value which is situated under the natural convection curve. During the second phase, the convection coefficient increases to get closer to the natural convection curve.

\section{Description of the numerical model}

The thickness of a building wall is small compared to its other dimensions. The conduction heat transfer is supposed to be unidirectional. Thus, the conduction model is onedimensional. It based on the finite volume method (see Patankar [22]). Each layer of the wall is divided into volumes, the expression of the energy balances for all the volumes are then gathered in the matrix equation 8. $\{T\}$ is a vector containing the temperature of all the volumes. $\left\{T_{\text {ext }}\right\}$ is a vector containing the temperature boundary conditions. The matrix $\left[A_{C}\right]$ contains the heat capacity of the volumes. $\left[A_{F}\right]$ and $\left[B_{F}\right]$ are used to calculate the total energy entering the volumes.

$$
\left[A_{C}\right] \cdot \frac{\partial\{T\}}{\partial t}=\left[A_{F}\right] \cdot\{T\}+\left[B_{F}\right] \cdot\left\{T_{e x t}\right\}
$$


The phase change is simulated using the effective heat capacity method. The expression of the PCM heat capacity as a function of the temperature is calculated using the DSC curve for melting PCM from figure2. Since the heat capacity of the PCM and the convection coefficients depend on the temperature of the wall, the matrix $\left[A_{C}\right],\left[A_{F}\right]$ and $\left[B_{F}\right]$ are temperature dependent. The equation 8 cannot be solved with an implicit scheme.

An iterative resolution method has been developed in order to avoid the use of an explicit scheme. The iterative method is performed for each time-step $\left[t_{k-1} ; t_{k}\right]$. The aim of the method is to obtain an approximation of the matrix $\left[A_{C}\right],\left[A_{F}\right]$ and $\left[B_{F}\right]$ at the time $t_{k}$.

The algorithm of the iterative method is represented on the figure $9 .\left\{T_{i}^{k}\right\}$ and $\left\{T_{i+1}^{k}\right\}$ are approximations of the temperatures $\left\{T^{k}\right\}$ at the time $t_{k}$. For each iterations, $\left[A_{C}\right]$, $\left[A_{F}\right]$ and $\left[B_{F}\right]$ are calculated with the temperatures $\left\{T_{i}^{k}\right\}$. A new approximation $\left\{T_{i+1}^{k}\right\}$ is obtained by solving the equation:

$$
\left[A_{C}\left(T_{i}^{k}\right)\right] \cdot \frac{\left\{T_{i+1}^{k}\right\}-\left\{T^{k-1}\right\}}{t_{k}-t_{k-1}}=\left[A_{F}\left(T_{i}^{k}\right)\right] \cdot\left\{T_{i+1}^{k}\right\}+\left[B_{F}\left(T_{i}^{k}\right)\right] \cdot\left\{T_{e x t}^{k}\right\}
$$

The vectors $\left\{T_{i}^{k}\right\}$ and $\left\{T_{i+1}^{k}\right\}$ are used to compute the errors $\epsilon_{F}$ and $\epsilon_{C} \cdot \epsilon_{F}$ is the error on the convection coefficient at the internal surface of the wall. It is obtained from the coefficients $h_{i}$ calculated for the iterations $i$ and $i+1$ :

$$
\epsilon_{F}=\sqrt{\frac{\left(h_{i+1}-h_{i}\right)^{2}}{h_{i}^{2}}}
$$

$\epsilon_{C}$ is the error on the heat capacity of the PCM. The heat capacities $\left(C_{p, i, j}^{k}\right)_{j=j_{P C M}}$ of the PCM volumes are calculated for the iterations $i$ and $i+1 . \epsilon_{C}$ is then obtained with the equation:

$$
\epsilon_{C}=\sqrt{\frac{\sum_{j=j_{P C M}}\left(C_{p, i+1, j}^{k}-C_{p, i, j}^{k}\right)^{2}}{\sum_{j=j_{P C M}}^{N_{P C M}}\left(C_{p, i, j}^{k}\right)^{2}}}
$$

Minium values $\epsilon_{R}^{\min }$ and $\epsilon_{C}^{m i n}$ are fixed for $\epsilon_{R}$ and $\epsilon_{C}$. Successive approximations of $\left\{T^{k}\right\}$ are calculated until both $\epsilon_{R}$ and $\epsilon_{C}$ have reached their minimum values.

The amount of energy $E_{P C M}^{k}$ stored in the PCM layer during the time step $\left[t_{k-1} ; t_{k}\right]$ is calculated from an averaged value of the heat capacity in each volume $j$, and the difference of the temperatures values between $t_{k-1}$ and $t_{k}$ :

$$
E_{P C M}^{k}=\sum_{j=j_{P C M}} \frac{C_{p, j}^{k-1}+C_{p, j}^{k}}{2}\left(T_{j}^{k}-T_{j}^{k-1}\right)
$$

Every simulation is performed for 7 days. The total amount of energy exchanged with the PCM layer during the last 24 hours is calculated with the following equation:

$$
E_{P C M}=\sum_{k=k_{24}} \max \left[E_{P C M}^{k}, 0\right]
$$




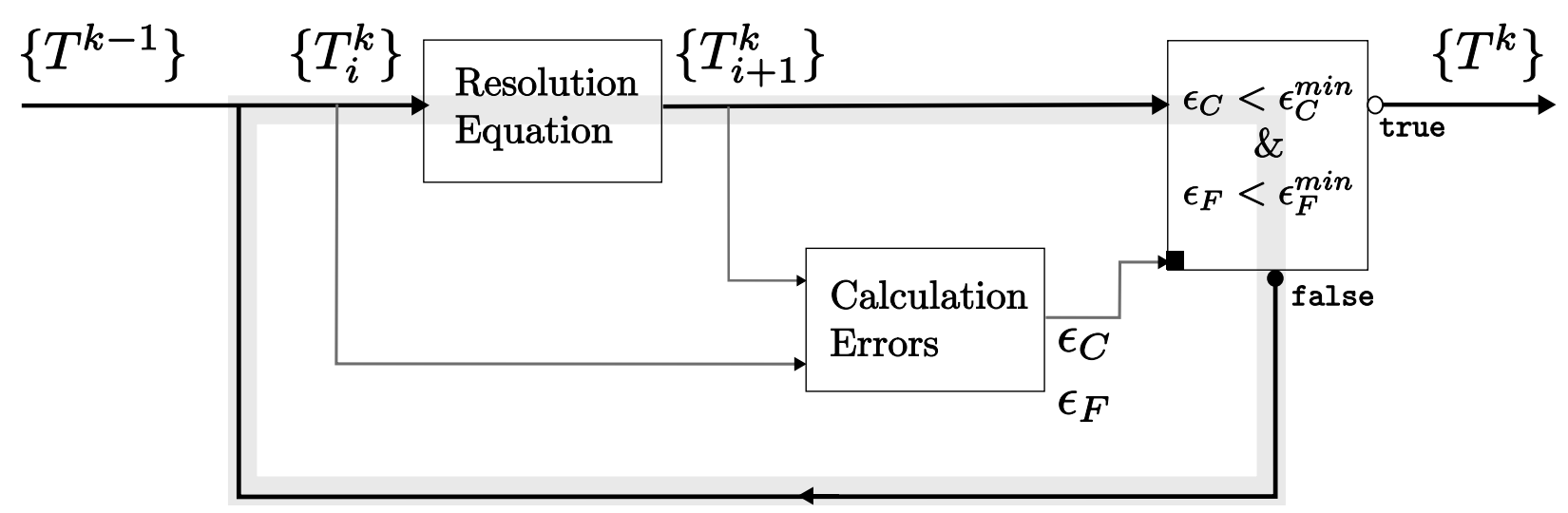

Figure 9: Schematic representation of the iterative resolution method.

An optimum number of 10 volumes per layer has been found for the present wall. The time-step duration is $2 \mathrm{~min}$. The values $\epsilon_{R}^{\min }$ and $\epsilon_{C}^{\min }$ are set to 0.001 .

\section{Results and discussions}

The simulations have been performed using different correlations for the convective heat transfer coefficient at the internal surface of the wall. Two sets of simulations have been executed. During the first set of simulations, no phase change occurs in the PCM layer. Its heat capacity is constant, equal to $2690 \mathrm{~J} / \mathrm{kgK}$, which corresponds to the heat capacity of the material ENERGAIN ${ }^{\circledR}$ between $30^{\circ} \mathrm{C}$ and $40^{\circ} \mathrm{C}$ : this is the reference case. During the second set of simulations, the phase change is simulated with the temperature dependency of the PCM heat capacity.

The energy $E_{P C M}$ stored in the PCM layer during the last $24 h$ is calculated for each simulation with the equation 13. The total energy $E_{T O T}$ stored in the wall during the last $24 h$ is also calculated in a similar manner than $E_{P C M}$. The difference of the total energy stored in the wall with and without phase change material, $\Delta E_{T O T}$, is calculated for each simulation. This value characterizes the energy storage improvement of the wall due to the phase change:

$$
\Delta E_{T O T}=\left(E_{T O T}\right)_{\text {with phase change }}-\left(E_{T O T}\right)_{\text {without phase change }}
$$

\subsection{Influence of the natural convection heat transfer coefficient}

Eight simulations have been executed using the correlation from Alamdari and Hammond [16], Awbi and Hatton [17], Liu and Awbi [18] and the RT2005 [13]. The results of those simulations are presented on the figure 10. $E_{P C M}$ lies between $71.6 k J$ and $64.4 k J$ if no phase change occurs, which implies a variation less than $12 \%$ due to the value of the convection coefficient.

The value of $E_{P C M}$ with phase change lies between $144 k J$ and $218 k J$. Thus, its variation due to the correlation for $h$ reaches $51 \%$. This variation is much higher with the presence of a phase change material in the wall than with classical constant density material. 


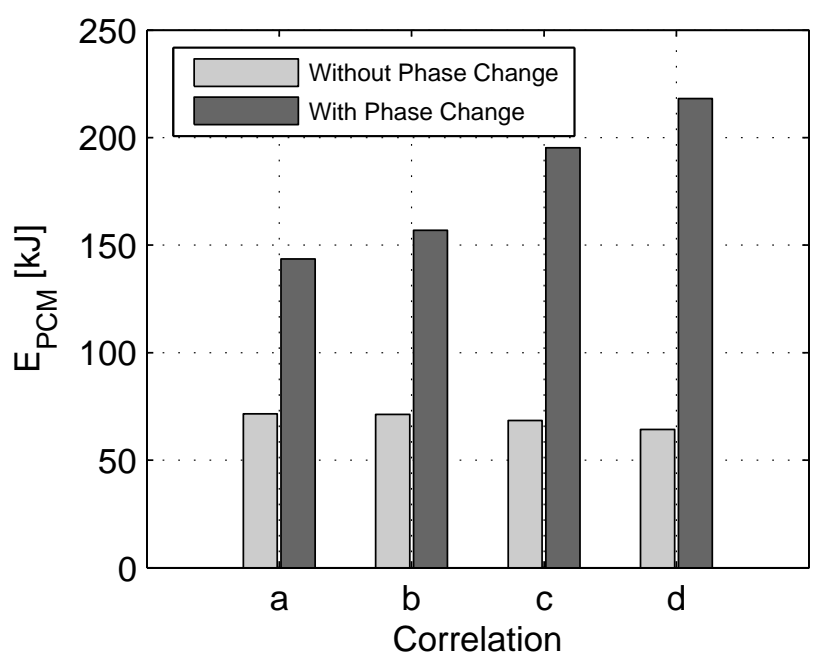

Figure 10: Energy exchanged with the PCM layer, influence of the correlation for $h$. a: Alamdari and Hammond [16], b: Awbi and Hatton [17], c: Liu and Awbi [18], d: RT2005 [13].

\begin{tabular}{ll} 
Correlation & $h\left[\mathrm{~W} / \mathrm{m}^{2}\right]$ \\
\hline $\begin{array}{l}\text { Alamdari and Hammond } \\
{[16]}\end{array}$ & 1.37 \\
\hline Awbi and Hatton [17] & 1.81 \\
\hline Liu and Awbi [18] & 3.86 \\
\hline RT2005 [13] & 7.7 \\
\hline
\end{tabular}

Table 2: Mean values of the convection coefficient during the last $24 h 00$

The figure 11 represents the the energy storage improvement of the wall due to the phase change for each correlation. $\Delta E_{T O T}$ varies from $46 k J$ with Alamdari and Hammond correlation, to $145 k J$ with the constant value of $h$ given by the RT2005. The variation of this value reaches almost $200 \%$. The correlations can be sorted by ascending order of $\Delta E_{T O T}$ in this way: Alamdari and Hammond [16] - Awbi and Hatton [17] - Liu and Awbi [18] - the RT2005 [13].

The figure 12 shows the values taken by the convective heat transfer coefficient during the last $24 h$ of the simulations with phase change. The mean values of those coefficients are given in the table 2. The sorting of the correlations in ascending order of $h$ is the same than the sorting previously defined. The results of the simulations show that the higher is the value of the convection coefficient, the more efficient is the PCM layer.

For the three first curves of the figure 12, the convection coefficient reaches a zero value at two different instants of the days. Those moments correspond to a temperature equilibrium between the ambient medium and the surface of the wall. 


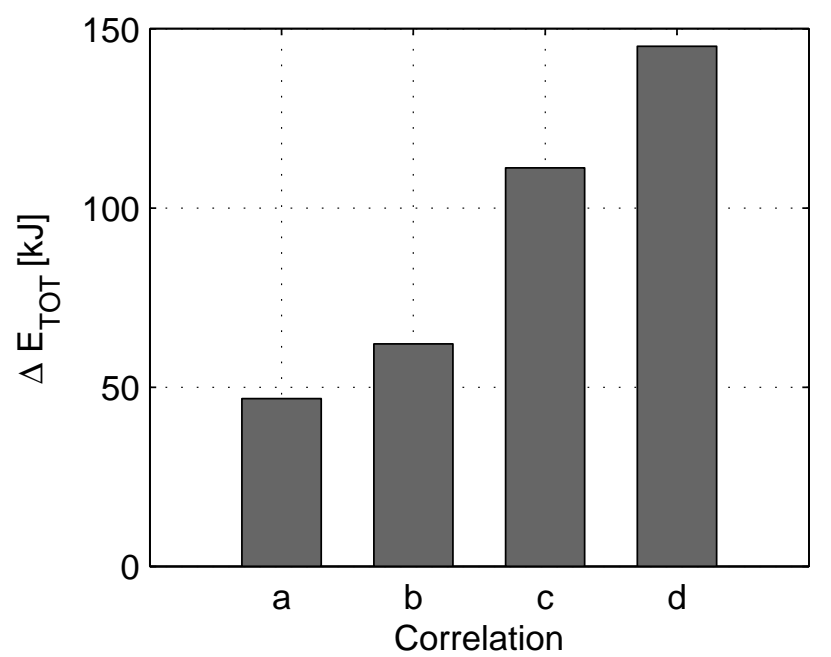

Figure 11: Total energy difference exchanged with the wall, influence of the correlation for $h$. a: Alamdari and Hammond [16], b: Awbi and Hatton [17], c: Liu and Awbi [18], d: RT2005 [13].

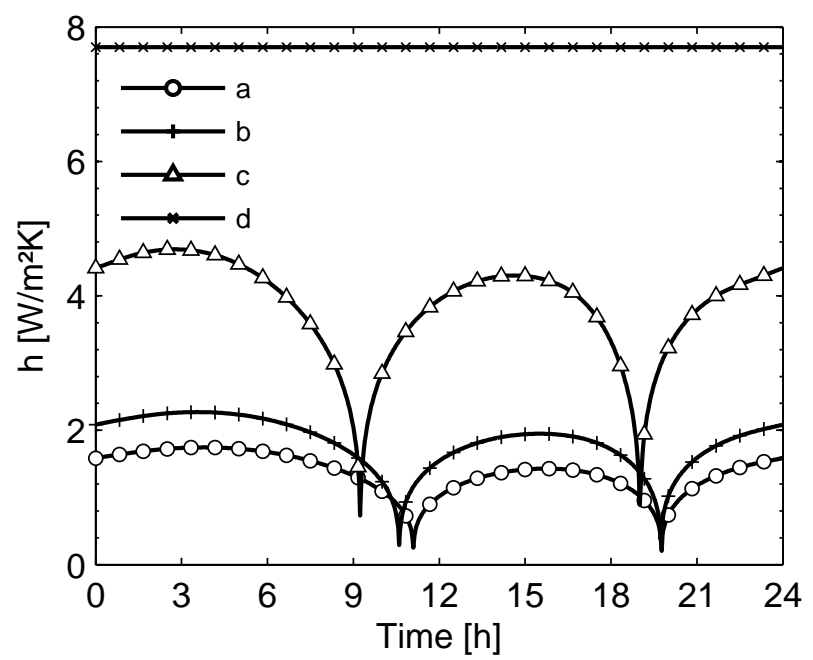

Figure 12: Values of the convective heat transfer coefficient during the last 24h00. a: Alamdari and Hammond [16], b: Awbi and Hatton [17], c: Liu and Awbi [18], d: RT2005 [13]. 


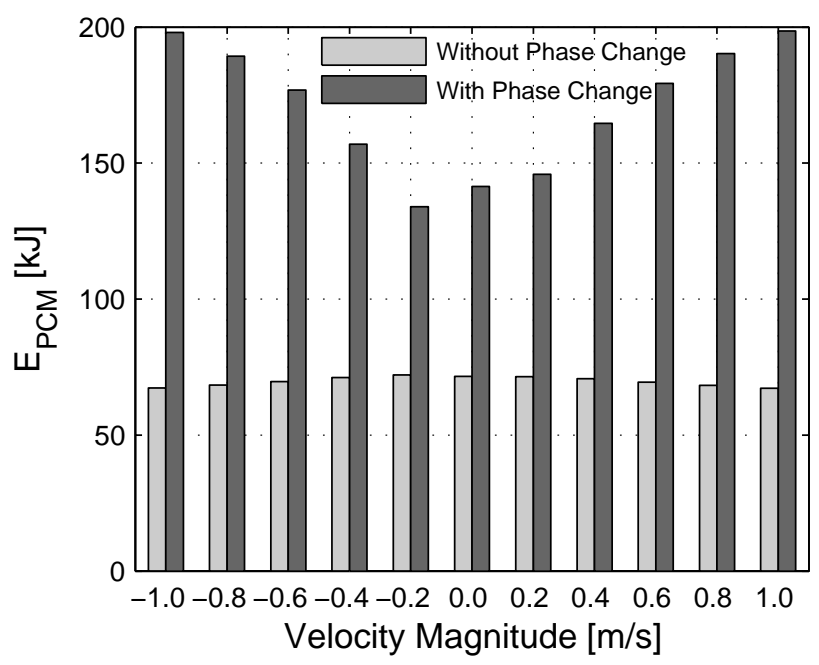

Figure 13: Energy exchanged with the PCM layer, influence of the air velocity.

\subsection{Influence of the air velocity for mixed convection}

The results presented in this section are obtained with the correlation 7 for mixed convection. The value and the direction of the air velocity $V$ due to the global movement in the room is supposed to be constant during the simulations. Different values of the velocity, situated between $-1 \mathrm{~m} / \mathrm{s}$ and $1 \mathrm{~m} / \mathrm{s}$ have been tested.

The results are shown in the figure 13. Once again, the modification of the convection coefficient due to the air velocity affects the results of the simulations with phase change in a larger extend than it affects the results of the simulations without phase change. The variation of $E_{P C M}$ for the simulations without phase change is less than $6.5 \%$; it is more than $30 \%$ with phase change.

For $V \geq 0.4 \mathrm{~m} / \mathrm{s}$, the value of $E_{P C M}$ obtained for the simulations with phase change increases when the absolute value of $V$ increases. This is no more true when $V<0.4 \mathrm{~m} / \mathrm{s}$. The figure 13 shows that the minimum value of $E_{P C M}$ does not correspond to $V=0 \mathrm{~m} / \mathrm{s}$, but to $V=-0.2 \mathrm{~m} / \mathrm{s}$. This tendency is also observed for the energy storage improvement of the wall due to the phase change, seen on figure 14. The minimum value of $\Delta E_{T O T}$ is obtained for $V=-0.2 \mathrm{~m} / \mathrm{s}$. Its variation from $V=-0.2 \mathrm{~m} / \mathrm{s}$ to $V=1 \mathrm{~m} / \mathrm{s}$ reaches $200 \%$.

The figures 15 and 16 represent the values taken by the convection coefficient during the last day of simulation, respectively for negative and positive values of $V$. When the absolute value of $V$ is sufficiently high, the convection is mainly forced convection. The fluctuations of the convection coefficient due to modifications of the temperature difference are damped. The mean value of $h$ increases when the absolute value of the velocity $V$ increases, leading to an augmentation of the amount of energy exchanged with the MCP layer of the wall.

When $|V|=0.2 \mathrm{~m} / \mathrm{s}$, the orders of magnitude of the natural and forced convection terms in the correlation 7 are the same. Since the temperature difference between the surface of the wall and the ambient medium oscillate around $0^{\circ} \mathrm{C}$, forced and natural convection alternate between opposing forces and assisting forces. This is why the convection coefficient 


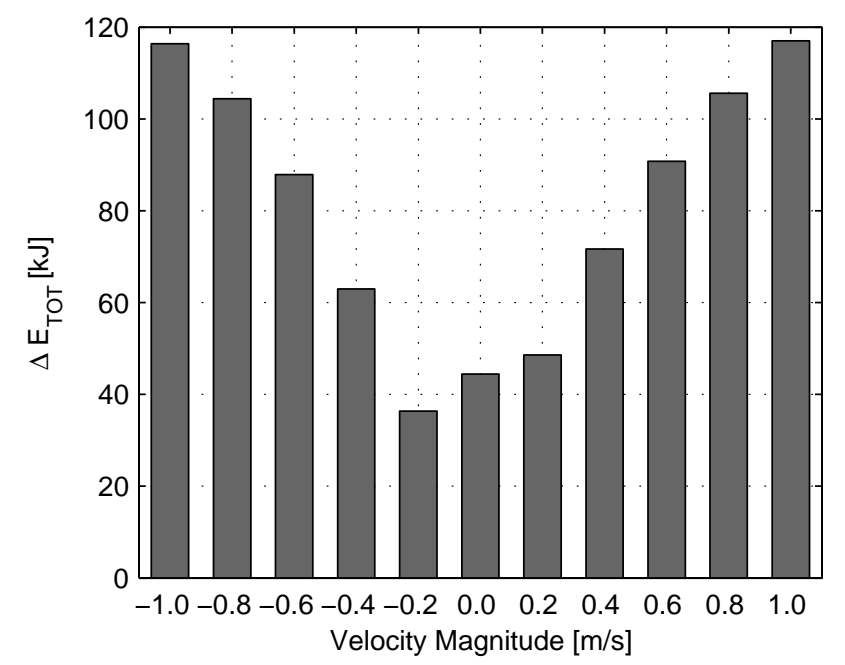

Figure 14: Total energy difference exchanged with the wall, influence of the air velocity.

for $|V|=0.2 \mathrm{~m} / \mathrm{s}$ is partly over, and partly below the convection coefficient for $V=0 \mathrm{~m} / \mathrm{s}$. The averaged value of the convection coefficient during the last day of simulations is:

$\star 1.33 \mathrm{~W} / \mathrm{m}^{2} \mathrm{~K}$ for $V=-0.2 \mathrm{~m} / \mathrm{s}$

$\star 1.29 \mathrm{~W} / \mathrm{m}^{2} \mathrm{~K}$ for $V=0 \mathrm{~m} / \mathrm{s}$

$\star 1.5 \mathrm{~W} / \mathrm{m}^{2} \mathrm{~K}$ for $V=0.2 \mathrm{~m} / \mathrm{s}$.

It has a minimum for $V=0 \mathrm{~m} / \mathrm{s}$. Thus, the minimum values of $E_{P C M}$ and $\triangle E_{T O T}$ for $V=-0.2 \mathrm{~m} / \mathrm{s}$ cannot be fully justified with the averaged value of the convection coefficient. The fluctuation of $h$ during the day also have an impact on the amount of energy exchanged with the PCM layer.

\section{Conclusions}

The incorporation of PCM in building walls is a way to enhance the storage capacity of light weight building envelope. The heat transfer process between the wall and the indoor air is natural, mixed or forced convection. In this paper, we have tested different correlations of the convective heat transfer coefficients for numerical modeling purpose.

First of all, simulations show that the storage capacity of the wall with PCM is more sensitive to the convective heat transfer than the wall without PCM. The convective heat transfer drives the heat storage/release power in the wall and then the energy storage capacity in a given configuration.

Several correlations from the literature have been used to evaluate the convective heat transfer coefficient for the natural convection situation. The variation of the energy stored within $24 h$ reaches $200 \%$ depending on the correlation. 


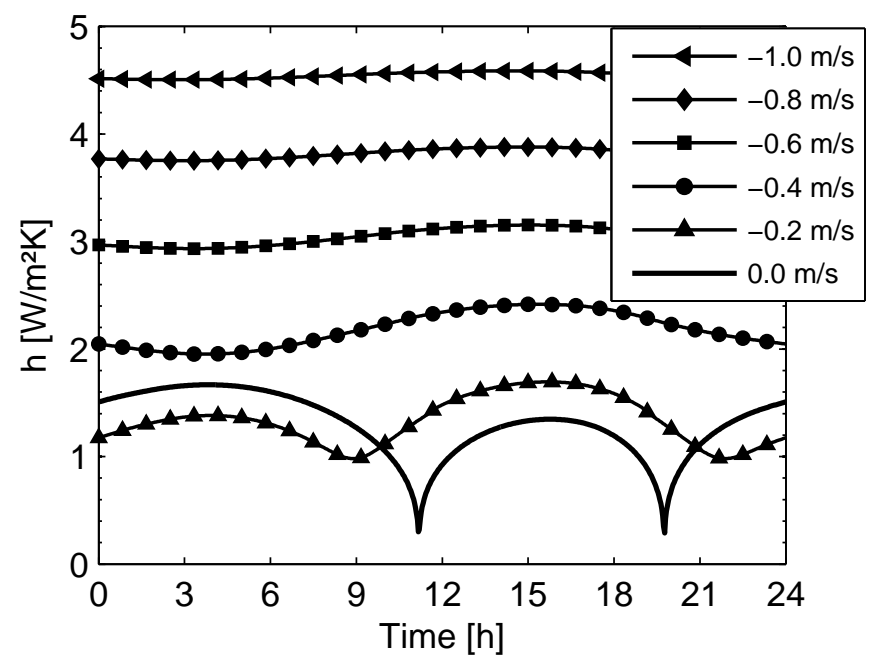

Figure 15: Values of the convective heat transfer coefficient during the last $24 h$ for $V \geq 0$.

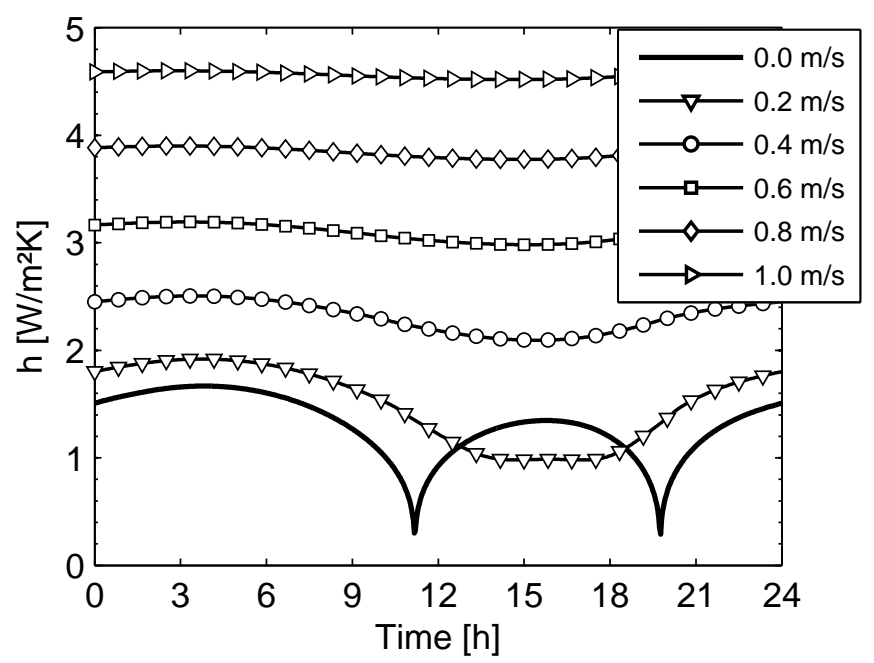

Figure 16: Values of the convective heat transfer coefficient during the last $24 h$ for $V \geq 0$. 
The effect of the air velocity has been studied with a mixed convection correlation deduced from the literature. The more the velocity is high and the more the energy stored in the PCM is important. Of course, this conclusion proves that over ventilation in summer must be used to enhanced the effect of the PCM.

The main limitation of this paper is that only correlations from the literature have been studied. Further investigations are needed to specifically study the natural convection in the presence of PCM walls.

\section{References}

[1] I. Dincer, M. Rosen, Thermal Energy Storage - Systems and Applications, Jhon Wiley and Sons, 2002.

[2] Climate plan 2004: let's act together to challenge of climate change, Tech. rep., French Ministry of Ecology and Sustainable Developpment (2004).

[3] V. V. Tyagi, D. Buddhi, Pcm thermal storage in buildings: A state of art, Renewable and Sustainable Energy Reviews 11 (6) (2007) 1146 - 1166.

[4] A. M. Khudhair, M. M. Farid, A review on energy conservation in building applications with thermal storage by latent heat using phase change materials, Energy Conversion and Management 45 (2) (2004) $263-275$.

[5] Y. Zhang, G. Zhou, K. Lin, Q. Zhang, H. Di, Application of latent heat thermal energy storage in buildings: State-of-the-art and outlook, Building and Environment 42 (6) (2007) $2197-2209$.

[6] F. Kuznik, D. David, K. Johannes, J.-J. Roux, A review on phase change materials integrated in building walls, Renewable and Sustainable Energy Reviews 15 (1) (2011) 379 - 391. doi:DOI: 10.1016/j.rser.2010.08.019.

[7] F. Kuznik, J. Virgone, J. Noel, Optimization of a phase change material wallboard for building use, Applied Thermal Engineering 28 (11-12) (2008) 1291 - 1298.

[8] ASTM, Standard test method for steady-state heat flux measurements and thermal transmission properties by means of the guarded-hot-plate apparatus- norm c177 (2004).

[9] L. Shilei, Z. Neng, F. Guohui, Impact of phase change wall room on indoor thermal environment in winter, Energy and Buildings 38 (1) (2006) 18 - 24.

[10] S. Scalat, D. Banu, D. Hawes, J. Parish, F. Haghighata, D. Feldman, Full scale thermal testing of latent heat storage in wallboard, Solar Energy Materials and Solar Cells 44 (1) (1996) 49 - 61.

[11] T. Lee, D. W. Hawes, D. Banu, D. Feldman, Control aspects of latent heat storage and recovery in concrete, Solar Energy Materials and Solar Cells 62 (3) (2000) 217 - 237.

[12] F. Kuznik, J. Virgone, Experimental assessment of a phase change material for wall building use, Applied Energy 86 (10) (2009) 2038 - 2046.

[13] Rt 2005, arrêté d'application du 24 mai 2006, journal officiel de la république franaise, texte 14, 2006.

[14] H. Awbi, Calculation of convective heat tranfer coefficient of room surfaces for natural convection, Energy and Buildings 28 (1998) 219-227.

[15] S. Churchill, R. Usagi, A standardized procedure for the producation of correlations in the form of a common empirical equation, Ind. Eng. Chem. 13 (1974) 39-44.

[16] F. Alamdari, G. Hammond, Improved data correlations for buoyancy-driven convection in rooms, Building Services Engineering Research and Technology 4 (1983) 106-112.

[17] H. Awbi, A. Hatton, Natural convection from heated room surfaces, Energy and Buildings 30 (1999) 233.

[18] H. Liu, H. Awbi, Performance of phase change material boards under natural convection, Building and Environment xxx (2009) 1-6.

[19] P. Wallenten, Convective heat transfer coefficient in a full-scale room with and without furniture, Building and Environment 36 (2001) 743-751.

[20] T. Chen, B. Armaly, N. Ramachandran, Correlations for laminar mixed convection flows on vertical, inclined, and horizontal flat plates, Journal of Heat Transfer 108 (1986) 835-840. 
[21] T. Chen, B. Armaly, M. Ali, Turbulent mixed convection along a vertical flat plate, Journal of Heat Transfer 109 (1987) 251-253.

[22] S. Patankar, Numerical heat transfer and fluid flow, Taylor \& Francis, 1980. 